\title{
Selective Mono-C-methylations of Arylacetonitriles and Arylacetates with Dimethylcarbonate: A Mechanistic Investigation
}

\author{
Pietro Tundo,* Maurizio Selva, Alvise Perosa, and Sofia Memoli \\ Dipartimento di Scienze Ambientali, Università Ca' Foscari, Dorsoduro 2137 - 30123 Venezia, I taly \\ tundop@univeit
}

Received December 13, 2000

\begin{abstract}
The very high mono-C-methylation selectivity (>99\%) of arylacetic acid derivatives $\left(\mathrm{ArCH}_{2} \mathrm{X} ; \mathrm{X}=\right.$ $\mathrm{CN}, \mathrm{CO}_{2} \mathrm{Me}$ ) with dimethyl carbonate (DMC) is due to a mechanism that involves consecutive methoxycarbonylation, methylation, and demethoxycarbonylation steps. I mportant aspects of this mechanism are clarified herein by a kinetic investigation. In the case of arylacetonitriles, at 140 ${ }^{\circ} \mathrm{C}$, the comparison of the rate constants of model reactions involving 2-phenyl propionitrile, phenylacetonitrile, 2-methoxycarbonyl phenylacetonitrile, and 2-methyl-2-methoxy carbonyl phenyl acetonitrile (compounds $\mathbf{1 a} \mathbf{-} \mathbf{4 a}$, respectively) with DMC indicates that the methylation process is the fastest and the irreversible step, which drives the overall reaction to completion. The situation is reversed for arylacetic esters, where the methylation is more difficult than the demethoxycarbonylation reaction; therefore, a higher reaction temperature is required.
\end{abstract}

\section{Introduction}

Under both continuous-flow and batch conditions and in the presence of $\mathrm{K}_{2} \mathrm{CO}_{3}$, arylacetic acid derivatives (2: $\mathrm{ArCH}_{2} \mathrm{X} ; \mathrm{X}=\mathrm{CN}, \mathrm{CO}_{2} \mathrm{Me}$ ) reacted with dimethyl carbonate (DMC) to afford the corresponding mono-C-methyl derivatives (2-aryl proprionitriles and methyl 2-aryl propionates, 1) with unprecedented selectivity (>99\%, eq a). ${ }^{1-5} \mathrm{~F}$ or example, in an autoclave at $180{ }^{\circ} \mathrm{C}$, phenylacetonitrile was transformed quantitatively into 2-phenylpropionitrile (>98\% yield) in 6 h. ${ }^{6}$ The same reaction carried out using methyl iodide under PTC conditions yielded a ratio between the monomethylated and dimethylated products that never exceeded 2.4. ${ }^{7}$

$$
\begin{aligned}
& \underset{2}{\mathrm{ArCH}_{2} \mathrm{X}}+\left(\mathrm{CH}_{3} \mathrm{O}\right)_{2} \mathrm{CO} \stackrel{\mathrm{K}_{2} \mathrm{CO}_{3}}{\longrightarrow} \\
& \operatorname{ArCH}\left(\mathrm{CH}_{3}\right) \mathrm{X}+\mathrm{CH}_{3} \mathrm{OH}+\mathrm{CO}_{2} \\
& \mathrm{X}=\mathrm{CN}, \mathrm{COOCH}_{3}
\end{aligned}
$$

Besides the excellent synthetic outcome, this methylation method is environmentally benign in character and fits the requirements for preventing pollution of chemical processes at the source, according to the general

\footnotetext{
* To whom correspondence should be addressed. Fax: +39-041-234 8620.

(1) Tundo, P. In Continuous Flow Methods in Organic Synthesis; Ellis Harwood, Ltd.: Chichester, U.K., 1991.

(2) Tundo, P.; Trotta, F.; Moraglio, G. J . Chem. Soc., Perkin Trans. 1 1989, 1070.

(3) Carruthers, W. In Some Modern Methods of Organic Synthesis, 3rd ed.; Cambridge University Press: Cambridge, 1989.

(4) Selva, M.; Marques, C. A.; Tundo, P. J . Chem. Soc., Perkin Trans. 1 1994, 1323-1328.

(5) Tundo, P.; Selva, M. Chemtech 1995, 25, 31-35

(6) Tundo, P.; Selva, M.; Bomben, A. Org. Synth. 1999, 76, 169177.

(7) Mikolajczyk, M.; Grzejszczak, S.; Zatorski, A.; Montanari, F.; Cinquini, M. Tetrahedron Lett. 1975, 3757.
}

objectives of Green Chemistry. 6,8 In fact, the reaction takes place in the presence of a weak base (usually $\mathrm{K}_{2}$ $\left.\mathrm{CO}_{3}\right)$ as a catalyst, uses a nontoxic alkylating agent (DMC), requires no solvent, and produces neither organic nor inorganic wastes to be disposed of. The only coproduct (methanol) can, in principle, be recycled for DMC production. ${ }^{9}$

As far as the mechanism is concerned, our experimental investigation of DMC-mediated alkylations supports the hypothesis that the reaction does not proceed through an $\mathrm{S}_{\mathrm{N}} 2$ displacement of the $\mathrm{ArCH}^{(-)} \mathrm{X}$ nucleophile $(\mathrm{X}=$ $\left.\mathrm{CN}, \mathrm{CO}_{2} \mathrm{Me}\right)$ on DMC ( $\mathrm{B}_{\mathrm{Al}} 2$ mechanism). ${ }^{4}$ Rather, the sel ectivity arises from two consecutive reactions involving two intermediate species, that is, $\mathrm{ArCH}\left(\mathrm{CO}_{2} \mathrm{Me}\right) \mathrm{X}(3)$ and $\operatorname{ArC}\left(\mathrm{CH}_{3}\right)\left(\mathrm{CO}_{2} \mathrm{Me}\right) \mathrm{X}(4)$, which are observed during the reaction (Scheme 1$){ }^{4}$

Initially, the carbanion $\left[\mathrm{ArCH}^{(-)} \mathrm{X}\right]$ undergoes a methoxycarbonylation reaction by attacking the acyl carbon of $\mathrm{DMC}\left(\mathrm{B}_{\mathrm{AC}} 2\right.$ mechanism); the resulting intermediate $\left[\mathrm{ArCH}\left(\mathrm{CO}_{2} \mathrm{Me}\right) \mathrm{X}, 3\right]$ reacts through its anion $\left[\mathrm{ArC}^{(-)}\right.$ $\left.\left(\mathrm{CO}_{2} \mathrm{Me}\right) \mathrm{X}, \mathbf{3}^{-}\right]$with the alkyl carbon of $\mathrm{DMC}$ to yield the corresponding methyl derivative $\left[\mathrm{ArC}\left(\mathrm{CH}_{3}\right)\left(\mathrm{CO}_{2} \mathrm{Me}\right) \mathrm{X}, \mathbf{4}\right.$; $\mathrm{B}_{\mathrm{Al}} 2$ mechanism]. Finally, compound $\mathbf{4}$ is subjected to a demethoxycarbonylation reaction to the final product $\left[\mathrm{ArCH}\left(\mathrm{CH}_{3}\right) \mathrm{X}\right]$.

With the aim of exploring this intriguing mechanism and the unusual selectivity, a detailed kinetic study of the reaction was begun: each step of Scheme 1 was considered separately, and the related kinetic constants were determined. This investigation proved to be fundamental to comprehending the reaction selectivity.

(8) (a) Tundo, P.; Anastas, P.; Black, D.; Breen, J .; Collins, T.; Memoli, S.; Miyamoto, J .; Polyakoff, M.; Tumas, W. PureAppl. Chem. 2000, 72, 1207. (b) Selva, M.; Tundo, P. In Green Chemistry: Designing Chemistry for theE nvironment; Anastas, P., Williamson, T., Eds.; ACS Symposium Series No. 626; American Chemical Society: Washington, DC, 1996; Chapter 7, pp 81-91.

(9) Delledonne, D.; Rivetti, F.; Romano U. J . Organomet. Chem. 1995, 488, c15. 
Scheme 1. Mechanism of Monomethylations of $\mathrm{CH}_{2}$-Active Compounds $\left(\mathrm{X}=\mathrm{CN}, \mathrm{CO}_{2} \mathrm{CH}_{3}\right)$ with Dimethyl Carbonate.

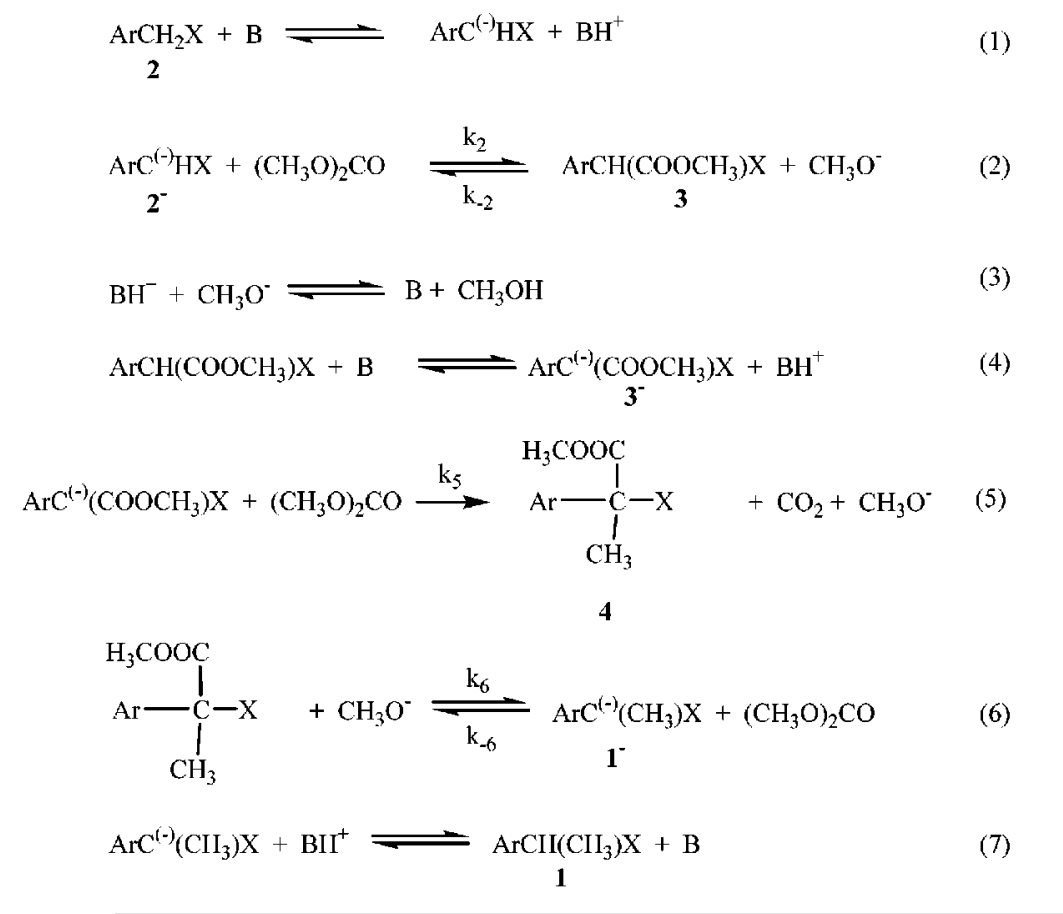

Overall reaction

$\underset{2}{\mathrm{ArCH}_{2} \mathrm{X}}+\left(\mathrm{CH}_{3} \mathrm{O}\right)_{2} \mathrm{CO} \longrightarrow \underset{1}{\mathrm{ArCH}\left(\mathrm{CH}_{3}\right) \mathrm{X}}+\mathrm{CO}_{2}+\mathrm{CH}_{3} \mathrm{OH}$

Table 1. Reaction Conditions for the Investigation of Steps 2, 5, and 6 of Scheme $\mathbf{1}^{\mathrm{a}}$

\begin{tabular}{|c|c|c|c|c|c|}
\hline entry & substrate (mmol) & $\mathrm{T}\left({ }^{\circ} \mathrm{C}\right)$ & $\begin{array}{c}\mathrm{K}_{2} \mathrm{CO}_{3} / \text { substrate } \\
\text { (molar ratio) }\end{array}$ & $\begin{array}{l}\mathrm{MeOH} / \text { substrate } \\
\text { (molar ratio) }\end{array}$ & $\begin{array}{c}\text { n-decane/substrate } \\
\text { (molar ratio) }\end{array}$ \\
\hline 1 & $\mathrm{PhCH}(\mathrm{Me}) \mathrm{CN}, \mathbf{l a}(1.52)$ & 140 & 2 & & b \\
\hline 2 & $\mathrm{PhCH}_{2} \mathrm{CN}, \mathbf{2 a}(1.71)$ & 140 & 2 & 10 & b \\
\hline 3 & $\mathrm{PhCH}\left(\mathrm{CO}_{2} \mathrm{Me}\right) \mathrm{CN}, 3 \mathrm{a}(1.14)$ & 140 & 2 & 10 & 0.3 \\
\hline 4 & $\left.\mathrm{PhC}(\mathrm{Me}) \mathrm{CO}_{2} \mathrm{Me}\right) \mathrm{CN}, \mathbf{4 a}(1.01)$ & 140 & $0.1-4^{c}$ & $10-30^{c}$ & 0.5 \\
\hline 5 & $\mathrm{~K}^{+} \mathrm{PhC}^{-}\left(\mathrm{CO}_{2} \mathrm{Me}\right) \mathrm{CN}, 3 \mathrm{a}^{-}(0.94)$ & $140-160$ & & & 0.2 \\
\hline 6 & $\mathrm{PhCH}\left(\mathrm{CO}_{2} \mathrm{Me}\right)_{2}, \mathbf{3 b}(0.96)$ & $140-160$ & 2 & 10 & b \\
\hline
\end{tabular}

a All reactions were carried out by using DMC in a 200 molar equiv excess with respect to the substrate. ${ }^{b}$ Internal standard was not used. ' Further details can be found in Table 2.

\section{Results and Discussion}

The methylation of phenylacetonitrile (Scheme 1, 2a: $\mathrm{Ar}=\mathrm{Ph}, \mathrm{X}=\mathrm{CN}$ ) was used as the model reaction. Although this reaction was generally carried out at $\mathrm{T} \geq$ $180^{\circ} \mathrm{C},{ }^{1-2,4}$ the study was done at a lower temperature $\left(140{ }^{\circ} \mathrm{C}\right)$ in order to decrease the reaction rate and allow a more accurate determination of the kinetic constants. All experiments were run in an autoclave since the alkylating agent (DMC) boils at $90{ }^{\circ} \mathrm{C}$. DMC itself was used in large excess (200 molar equiv) with respect to $2 \mathrm{a}$ and acted as the solvent. $\mathrm{K}_{2} \mathrm{CO}_{3}$ was al ways utilized as the base. ${ }^{10}$ If not otherwise specified, the reaction mixture was magnetically stirred at $650 \mathrm{rpm}$. Table 1 reports the conditions. Reactions were followed by GLC and GC/MS, on samples withdrawn at intervals from the autoclave. Steps 2, 5, and 6 of Scheme 1 were considered, while very fast acid-base equilibria (eqs $1,3,4$, and 7 ) were not.

(10) Although we al ready demonstrated that $\mathrm{K}_{2} \mathrm{CO}_{3}$ could certainly act as a catalyst (in a $5 \%$ molar amount with respect to $\mathrm{ArCH}_{2} \mathrm{X}$ ), ${ }_{4}$ in order to follow the reactions more conveniently, they were all performed using an excess of the base ( 2 molar equiv).
Methoxycarbonylation of 2a: Step 2. A mixture of the substrate, $\mathrm{DMC}$, and $\mathrm{K}_{2} \mathrm{CO}_{3}$ was made to react in a 1:200:2 molar ratio. At $140{ }^{\circ} \mathrm{C}$, the reaction proceeded very slowly: after $25 \mathrm{~h}$, only a $10 \%$ conversion was reached with the formation of the methylmethoxycarbonylated derivative $\mathrm{PhC}(\mathrm{Me})\left(\mathrm{CO}_{2} \mathrm{Me}\right) \mathrm{CN}$ (4a) as the sole product. The corresponding kinetic constant $\left(\mathrm{k}_{2}\right)$ was not determined.

However, under the same reaction conditions but at a higher temperature $\left(180-200^{\circ} \mathrm{C}\right)$, a number of different $\mathrm{CH}_{2}$-acidic compounds such as aryloxiacetic acid derivatives $\left(\mathrm{ArOCH}_{2} \mathrm{X} ; \mathrm{X}=\mathrm{CN}, \mathrm{CO}_{2} \mathrm{Me}\right.$ ) and alkylbenzyl sulfones $\left(\mathrm{ArCH}_{2} \mathrm{SO}_{2} \mathrm{R} ; \mathrm{R}=\mathrm{Ar}\right.$, alkyl) were selectively monomethylated with DMC. ${ }^{11}$ In all cases, reactions proceeded through methoxycarbonylated intermediates, but importantly, the direct methylation of the monomethyl derivatives [ $\mathrm{ArOCH}(\mathrm{Me}) \mathrm{X}$ and $\left.\mathrm{ArCH}(\mathrm{Me}) \mathrm{SO}_{2} \mathrm{R}\right]$ was never observed unless at temperatures over $220^{\circ} \mathrm{C}$. $\alpha$-Methylated benzyl ketones [ $\mathrm{ArCH}(\mathrm{Me}) \mathrm{COR}]$ behaved similarly. ${ }^{12}$

The reaction of alcohols with DMC was even more exclusive: only methoxycarbonylated products $\left(\mathrm{ROCO}_{2}-\right.$ 


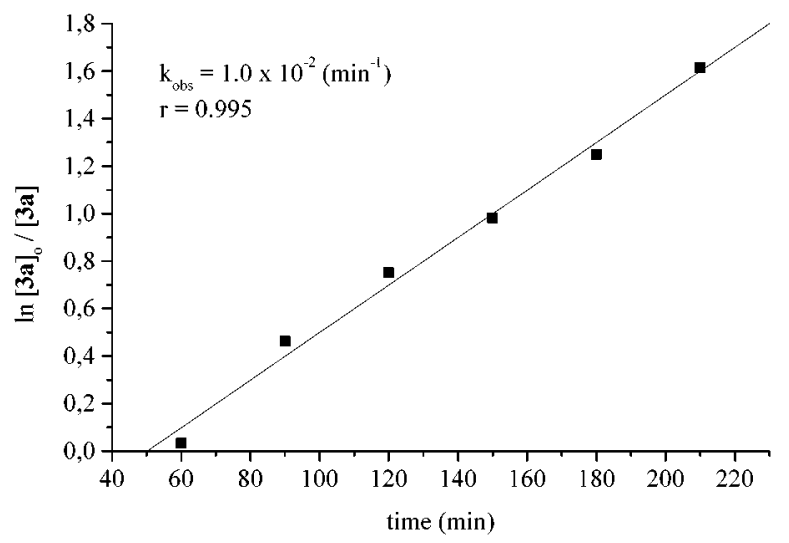

Figure 1. Reaction of 2-methoxycarbonylphenylacetonitrile (3a) with DMC. Determination of first-order rate constant.

Me, with no trace of methyl derivatives) were obtained at $220{ }^{\circ} \mathrm{C}$ and above. ${ }^{1}$

Moreover, it was observed that the reaction of DMC with 2-phenylpropionitrile $\left[\mathrm{PhCH}\left(\mathrm{CH}_{3}\right) \mathrm{CN}, \mathbf{1 a}\right]$ did not yield the doubly methylated derivative $\left[\mathrm{PhC}\left(\mathrm{CH}_{3}\right)_{2} \mathrm{CN}\right]$ even operating at $160^{\circ} \mathrm{C}$ and for prolonged reaction times (18 h).

In light of these results, structural and acidity factors strongly suggested that the direct methylation of $\mathbf{2 a}$ (via a $\mathrm{B}_{\mathrm{Al}} 2$ mechanism) with DMC could also be reasonably ruled out. Therefore, the formation of the product $\mathbf{4 a}$ in the investigated reaction (step 2) had to occur through the initial methoxycarbonylation of the reagent (2a) followed by a subsequent methylation.

Presently, there are no clear reasons why the anion $\mathbf{3} \mathbf{a}^{-}$undergoes methylation while $\mathbf{2} \mathbf{a}^{-}$does not. A possible explanation could lay in the hard-soft character of the involved moieties: the methoxycarbonylation of the more stabilized anion $\mathbf{3} \mathbf{a}^{-}$is probably much slower (and reversible) than that of the less hindered (and more reactive) $\mathbf{2} \mathbf{a}^{-}$. Therefore, the observed behavior would be due to the high acidity of $\mathbf{3 a}$ rather than to a high reactivity of $\mathbf{3 a}^{-}$. Also, a factor that should account for the different nucleophilicity of $\mathbf{2} \mathbf{a}^{-}$and $\mathbf{3} \mathbf{a}^{-}$is that the reaction takes place in the presence of a solid base; therefore, surface phenomena may affect the reaction outcome (see later). Indirect evidence comes from the DMC-methylation of arylacetonitriles, promoted by homogeneous strong bases (phosphazenes): ${ }^{4}$ in this case, the reaction is no longer selective since the double methylation of the substrates occurs to a large extent.

These aspects are, however, beyond the scope of the present work, the aim of which is to understand and describe the reaction selectivity through a kinetic investigation.

Demethoxycarbonylation and Methylation of 3a: Steps 2 and 5. 2-M ethoxycarbonylphenylacetonitrile (3a), the key intermediate of both equilibrium 2 and reaction 5, was used for the investigation of these two steps. Experiments were carried out by reacting a mixture of 3a, DMC, $\mathrm{K}_{2} \mathrm{CO}_{3}$, and methanol in a 1:200:2: 10 molar ratio. Methanol was used to make experimental

(11) (a) Bomben, A.; Marques, C. A.; Selva, M.; Tundo, P. Tetrahe dron 1995, 51, 11573. (b) Selva, M.; Bomben, A.; Tundo P. J . Chem. Res., Synop 1997, 448-449.

(12) Selva, M.; Marques, C. A.; Tundo P. Gazz. Chim. It. 1993, 123, 515-518. conditions of reactions 2 and 5 comparable to those of reaction 6 , which requires this reagent (see later).

From a kinetic standpoint, reactions 2 and 5 are a set of competitive reactions (eq b):

$$
\mathbf{2 a} \underset{\mathrm{k}_{-2}}{\stackrel{\mathrm{k}_{2}}{\rightleftharpoons}} \mathbf{3} \mathbf{a} \stackrel{\mathrm{k}_{5}}{\longrightarrow} \mathbf{4 a}
$$

where $k_{2}, k_{-2}$, and $k_{5}$ are the corresponding kinetic constants. ${ }^{13}$ However, since the methoxycarbonylation reaction of $\mathbf{2 a}(\mathbf{2} \mathbf{a} \rightarrow \mathbf{3} \mathbf{a})$ was much slower than its reverse reaction $\left(\mathbf{3 a} \rightarrow \mathbf{2 a}\right.$ ), eq b was simplified by placing $\mathrm{k}_{2} \ll$ $k_{-2}$ (eq c):

$$
\mathbf{2} \mathbf{a} \stackrel{\mathrm{k}_{-2}}{\longleftarrow} \mathbf{3} \mathbf{a} \stackrel{\mathrm{k}_{5}}{\longrightarrow} \mathbf{4 a}
$$

Eq c yields a first-order rate law expression for the disappearance of $\mathbf{3 a}$ with time (eq d):

$$
\begin{aligned}
-d[\mathbf{3} \mathbf{a}] / \mathrm{dt}=\mathrm{k}_{-2}[\mathbf{3} \mathbf{a}]+\mathrm{k}_{5}[\mathbf{3} \mathbf{a}]= \\
\left(k_{-2}+k_{5}\right)[\mathbf{3} \mathbf{a}]=k[\mathbf{3} \mathbf{a}](\mathrm{d})
\end{aligned}
$$

where $\mathrm{k}=\mathrm{k}_{-2}+\mathrm{k}_{5}$. According to eq $\mathrm{d}$, the substrate $\mathbf{3 a}$ follows a pseudo-first-order rate law (Figure 1). This reaction was repeated three times, and an average $\mathrm{k}_{\text {obs }}$ of $1.1 \times 10^{-2} \mathrm{~min}^{-1}$ was calculated.

The formations of $\mathbf{2 a}$ and $\mathbf{4 a}\left[\mathrm{PhC}\left(\mathrm{CH}_{3}\right)\left(\mathrm{CO}_{2} \mathrm{CH}_{3}\right) \mathrm{CN}\right]$ are given, respectively, by (Scheme 1 ):

$$
\begin{aligned}
\mathrm{d}[\mathbf{2} \mathbf{a}] / \mathrm{dt}=\mathrm{k}_{-2}[\mathbf{3} \mathbf{a}]= & \mathrm{k}_{-2}[\mathbf{3} \mathbf{a}]_{\mathrm{O}} \mathrm{e}^{-\mathrm{kt}} \text { or }[\mathbf{2} \mathbf{a}]= \\
& {[\mathbf{2} \mathbf{a}]_{0}+\left(\mathrm{k}_{-2} / \mathrm{k}\right)[\mathbf{3} \mathbf{a}]_{0}\left(1-\mathrm{e}^{-\mathrm{kt}}\right) }
\end{aligned}
$$

and

$$
\mathrm{d}[\mathbf{4} \mathbf{a}] / \mathrm{dt}=\mathrm{k}_{5}[\mathbf{3} \mathbf{a}]-\mathrm{k}_{6}[\mathbf{4 a}]+\mathrm{k}_{-6}[\mathbf{1} \mathbf{a}]
$$

where $\mathbf{l a}$ was the monomethyl derivative $\left[\mathrm{PhCH}\left(\mathrm{CH}_{3}\right)\right.$ CN].

Eq f was simplified by applying the following considerations. (i) The reaction of $3 a$ with DMC showed that the concentration of $\mathbf{1 a}$ was low compared to that of $\mathbf{3 a}$ until the latter was present, being [3a] $\approx 7[\mathbf{1 a}]$ throughout all the reaction. (ii) An independent investigation of step 6 indicated that the methoxycarbonylation of the monomethyl derivative $(\mathbf{1} \mathbf{a} \rightarrow \mathbf{4 a})$ occurred very slowly: $\mathrm{k}_{-6}$ has to be very small in comparison to $\mathrm{k}_{2}$.

Therefore, eq $f$ gives eq $g$ by omitting the term k-6[1a]:

$$
\mathrm{d}[\mathbf{4 a}] / \mathrm{dt}=\mathrm{k}_{5}[\mathbf{3 a}]-\mathrm{k}_{6}[\mathbf{4 a}]
$$

Since $[\mathbf{4 a}]_{0}=0$, one may assume that the condition $k_{5}[3 \mathbf{a}]$ $\gg k_{6}[\mathbf{4 a}]$ can be verified for a certain reaction time (see later). If so, eq $\mathrm{g}$ is further simplified to the following:

$$
\mathrm{d}[\mathbf{4 a}] / \mathrm{dt}=\mathrm{k}_{5}[\mathbf{3 a}]
$$

and considering that also $[\mathbf{2} \mathbf{a}]_{0}=0$, the combination of eqs e and $h$ yields:

(13) Scheme 1 should dictate the use of carbanion concentrations $\left(\mathbf{2} \mathbf{a}^{-}, \mathbf{3} \mathbf{a}^{-}\right)$rather than [2a] and [3a] in kinetic equations. However, whatever the concentrations of $2 \mathbf{a}^{-}$and $3 \mathbf{a}^{-}$are, ratios $\mathbf{2 a} / \mathbf{2} \mathbf{a}^{-}$and $3 a / 3 a^{-}$must be constant throughout the reaction (steps 2 and 5); the apparent simplification of eq b, which serves as a working hypothesis, does not alter kinetic results. 


$$
[\mathbf{2 a}] /[\mathbf{4 a}]=\mathrm{k}_{-2} / \mathrm{k}_{5}
$$

Eq i means that the ratio between $\mathbf{2} \mathbf{a}$ and $\mathbf{4 a}$ should remain constant and independent from the concentration of the reagent 3a. Eq i was validated experimentally. As can be seen in Figure $2 a$ (solid line), when 3a was made to react with $\mathrm{DMC}$, the ratio [2a]/[4a] remained unaltered (0.3). Moreover, the plot of the concentration of the product $2 \mathbf{a}$ versus $\left(1-\mathrm{e}^{-k t}\right)$ showed a good linear correlation (Figure $2 b$ ), which proved the pseudo-firstorder assumed by eq e.

Since the investigated reactions take place in the presence of a heterogeneous catalyst $\left(\mathrm{K}_{2} \mathrm{CO}_{3}\right)$, it should be noted that the rate may also depend on diffusion phenomena of reactants/products on the solid surface. We have already reported this in the particular case of methylation of phenylacetonitrile, for which it was shown that conversions were dependent on the stirring rate of the reaction mixture. ${ }^{6}$ To account for this fact, the reaction of $\mathbf{3 a}$ with DMC was also investigated by applying different stirring rates $\left(v_{\text {stir }}\right)$. Results are reported in Table 2.

A mass transport limitation seemed to occur at low $v_{\text {stir }}$ (compare conversion/time in entries 1-3). However, the ratio [2a]/[4a] was substantially the same $(0.3)$ in all cases, meaning that the ratio between rates of demethoxycarbonylation and methylation of 3 a was also free from a diffusion control. Even if the amount of the anion $\mathbf{3} \mathbf{a}^{-}$ (from which both compounds $\mathbf{2} \mathbf{a}$ and $\mathbf{4 a}$ are derived) did depend on the stirring, it was not necessary to measure its actual concentration in the reaction mixture (and hence, the equilibrium constant of eq 4 in Scheme 1). Therefore, for kinetic cal culations, the reagent concentration measured (by GC) as $[\mathbf{3 a}]_{\text {meas }}=\left\{[\mathbf{3 a}]_{\text {sol }}+\left[\mathbf{3 a}^{-}\right]\right\}$ (where [3a $]_{\text {sol }}$ was the reagent concentration in solution) appeared to be adequate. ${ }^{14}$ Bearing this in mind, we were able to determine the rate constants $\mathrm{k}_{-2}$ and $\mathrm{k}_{5}$ from the combination of eqs $d$ and $i$ :

$$
\left\{\begin{array}{l}
\mathrm{k}=\mathrm{k}_{-2}+\mathrm{k}_{5} \\
{[\mathbf{2 a}] /[\mathbf{4 a}]=\mathrm{k}_{-2} / \mathrm{k}_{5}}
\end{array}\right.
$$

The solution of this system gave $\mathrm{k}_{-2}=2.5 \times 10^{-3} \pm 3 \times$ $10^{-4} \mathrm{~min}^{-1}$ and $\mathrm{k}_{5}=7.9 \times 10^{-3} \pm 2 \times 10^{-4} \mathrm{~min}^{-1} .^{15}$

These data show that $\mathrm{k}_{5} \approx 3 \mathrm{k}_{-2}$, i.e., the methylation of 3a (step 5) occurs faster than its demethoxycarbonylation (step 2). This also proved that kinetic analyses of the reactions of DMC with $\mathbf{2} \mathbf{a}$ and $\mathbf{3 a}$ were in good agreement: when compound $\mathbf{3} \mathbf{a}$ was formed from $\mathbf{2} \mathbf{a}$, it readily reacted to give $\mathbf{4 a}$; again, the direct reaction of 3a with DMC afforded $\mathbf{4 a}$ faster than $\mathbf{2 a}$. The methylation step being more rapid than the methoxycarbonylation and the demethoxycarbonylation ones pushed the reaction onward.

This behavior may also explain some results previously reported: ${ }^{4}$ for a set of different acetonitriles $\left(\mathrm{ArCH}_{2} \mathrm{CN}\right.$; Ar: $\mathrm{XC}_{6} \mathrm{H}_{4} ; \mathrm{X}=\mathrm{H}, \mathrm{p}-\mathrm{Me}$, o-Me, $\mathrm{p}-\mathrm{F}, \mathrm{p}-\mathrm{Cl}, \mathrm{o}-\mathrm{MeO}, \mathrm{p}-\mathrm{MeO}$, $\mathrm{m}-\mathrm{MeO})$, it was observed that the concentration of the

(14) Before GC analysis, all samples of the reaction mixture were acidified.

(15) Since the reaction of 3a with DMC was repeated three times, three different $k$ values were available. The system i was solved by coupling the corresponding $\mathrm{k}$ value to a set of six values of the [2a]/ [4a] ratio (calculated for each sample analyzed during such reactions). Thus, the determination of both $\mathrm{k}_{-2}$ and $\mathrm{k}_{5}$ was averaged over a total of 18 solutions of $i$.
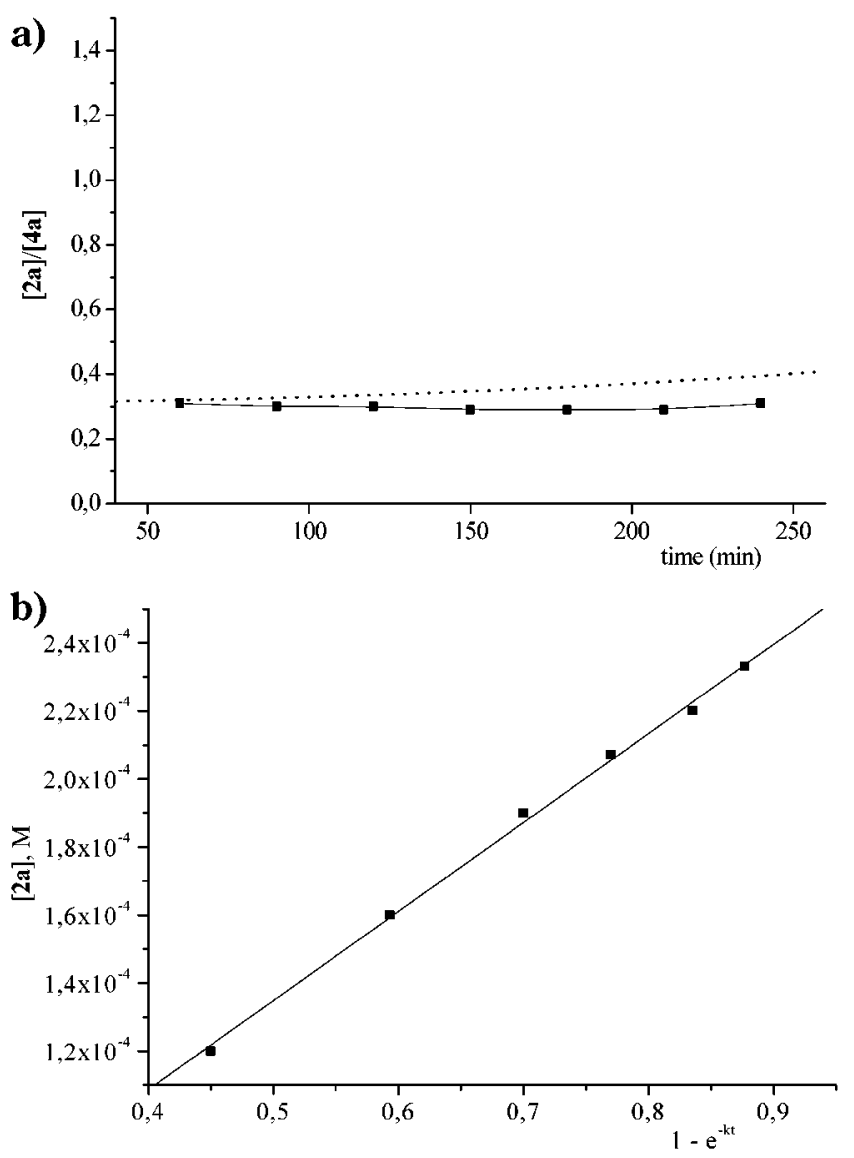

Figure 2. (a) Concentration ratio [2a]/[4a] during the reaction of $3 a$ with DMC, at $140{ }^{\circ} \mathrm{C}$. Solid line, experimental course; dashed line, predicted curve from eq $\mathrm{n}$. (b) Molar concentration of $\mathbf{2} \mathbf{a}$ versus $1-\mathrm{e}^{-\mathrm{kt}}$ during the reaction of $\mathbf{3 a}$ with $\mathrm{DMC}$.

Table 2. Reaction of 3a with DMC Carried Out at $140{ }^{\circ} \mathrm{C}$

\begin{tabular}{|c|c|c|c|c|c|c|c|}
\hline \multirow[b]{2}{*}{ entry } & \multirow{2}{*}{$\begin{array}{l}\text { stirring } \\
\text { rate } \\
\text { (rpm) }\end{array}$} & \multirow{2}{*}{$\begin{array}{c}\text { reaction } \\
\text { time } \\
\text { (min) }\end{array}$} & \multirow{2}{*}{$\begin{array}{c}\text { conversion } \\
\text { (\%) }\end{array}$} & \multicolumn{3}{|c|}{$\begin{array}{l}\text { products, } \\
\text { (\% by GC) }\end{array}$} & \multirow{2}{*}{$\begin{array}{c}\text { ratio of } \\
\mathbf{2 a} / \mathbf{4 a}\end{array}$} \\
\hline & & & & $\overline{\mathbf{l a}}$ & $2 a$ & $\overline{4 a}$ & \\
\hline $\begin{array}{l}1 \\
2 \\
3 \\
4 \\
5\end{array}$ & $\begin{array}{r}300 \\
650 \\
1100\end{array}$ & $\begin{array}{r}80 \\
150 \\
210 \\
120 \\
240\end{array}$ & $\begin{array}{r}67 \\
83 \\
97 \\
92 \\
100\end{array}$ & $\begin{array}{r}9 \\
13 \\
47 \\
28 \\
58\end{array}$ & $\begin{array}{l}14 \\
16 \\
12 \\
14 \\
10\end{array}$ & $\begin{array}{l}44 \\
54 \\
38 \\
50 \\
32\end{array}$ & $\begin{array}{l}0.31 \\
0.30 \\
0.32 \\
0.28 \\
0.31\end{array}$ \\
\hline
\end{tabular}
with Different Stirring Rates

a All reactions were carried out with a mixture of $\mathbf{3 a}$, DMC $\mathrm{K}_{2} \mathrm{CO}_{3}$, and $\mathrm{MeOH}$ in a 1:30:2:10 molar ratio.

methoxycarbonyl intermediate $\left[\mathrm{ArCH}\left(\mathrm{CO}_{2} \mathrm{Me}\right) \mathrm{CN}, 3\right]$ was al ways much lower than that of the methylmethoxycarbonyl intermediate $\left[\mathrm{ArC}(\mathrm{Me})\left(\mathrm{CO}_{2} \mathrm{Me}\right) \mathrm{CN}, 4\right]{ }^{16}$

It should be stressed, however, that all the above considerations as well as the evaluation of constants $\mathrm{k}_{-2}$ and $k_{5}$ rely on the occurrence of the inequality $k_{5}[3 a] \gg$ $\mathrm{k}_{6}[\mathbf{4 a}]$. Under which conditions does this relation hold? Obviously, the answer requires the determination of the $\mathrm{k}_{6}$ constant related to the demethoxycarbonylation of $\mathbf{4 a}$.

Demethoxycarbonylation of 4a: Step 6. The reaction of 2-methoxycarbonyl-2-phenyl propionitrile (4a) with methanol was investigated by using a mixture of the substrate, $\mathrm{DMC}, \mathrm{K}_{2} \mathrm{CO}_{3}$, and methanol in a 1:200:2:10 molar ratio. The disappearance of the substrate with time

(16) However, el ectron-withdrawing substituents (i.e., $\mathrm{p}-\mathrm{Cl}$ and p-F) seemed to speed up the overall reaction, probably through a stabilization of the involved carbanions. 


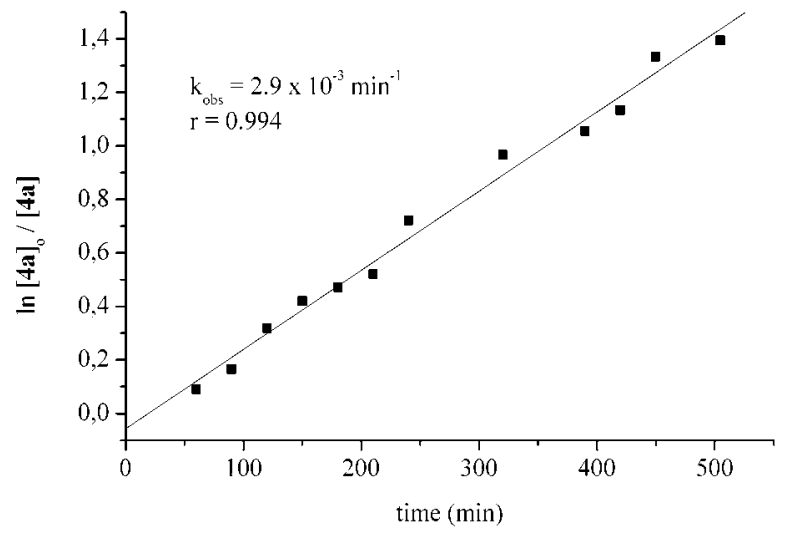

Figure 3. Demethoxycarbonylation reaction of $\mathbf{4 a}$ (step 6 of Scheme 1).

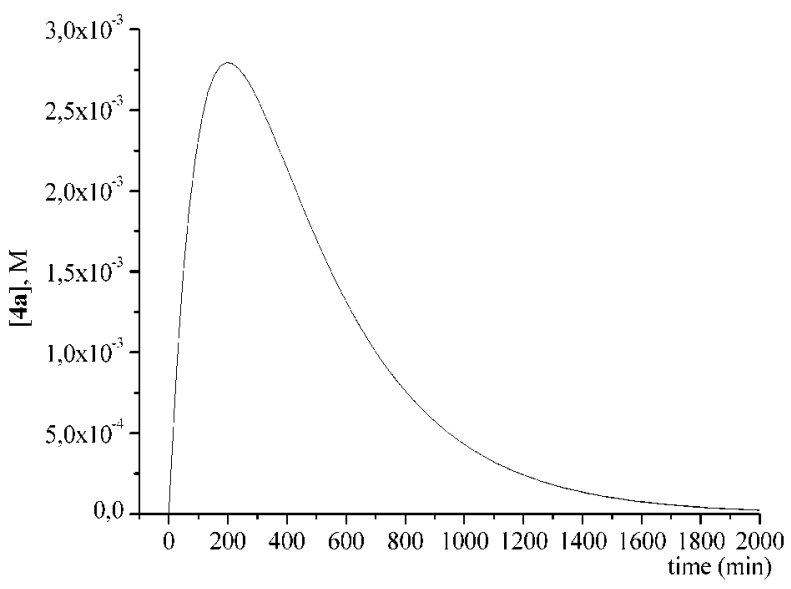

Figure 4. Molar concentration of $\mathbf{4 a}$ during the reaction of 3a with DMC. As calculated from eq $\mathrm{m}$.

followed a pseudo-first-order law (Figure 3) from which the rate constant, determined by repeating the reaction three times, was $\mathrm{k}_{\mathrm{obs}}=2.9 \times 10^{-3} \mathrm{~min}^{-1}$.

From Scheme 1, the rate of disappearance of $\mathbf{4 a}$ is given by the following: ${ }^{17}$

$$
-\mathrm{d}[\mathbf{4 a}] / \mathrm{dt}=\mathrm{k}_{6}[\mathbf{4 a}]-\mathrm{k}_{-6}[\mathbf{1 a}]
$$

The methoxycarbonylation of $\mathbf{1 a}$ with DMC was extremely slow (only $8 \%$ conversion after $25 \mathrm{~h}$ ), $\mathrm{k}_{-6} \ll \mathrm{k}_{6}$. Hence, $\mathrm{k}_{\mathrm{obs}}=\mathrm{k}_{6}$.

With both constants $k_{5}$ and $k_{6}$ determined, the range of validity for eq $h$ (i.e., of the inequality $k_{5}[3 a] \gg k_{6}$ [4a]) can be estimated through the integrated form of eq g:

$$
[\mathbf{4 a}]=k_{5} /\left(k_{5}-k_{6}\right)[\mathbf{3 a}]_{0}\left[e^{-k_{6} t}-e^{-k_{5} t}\right] \quad(m)^{18}
$$

The comparison of this concentration profile (eq m, Figure 4) with the one of the reagent $3 a$ (Figure 1 ) shows that, as far as the reaction of $3 \mathbf{3}$ with DMC proceeds to a $40 \%$ conversion ( $100 \mathrm{~min})$, the condition $\mathrm{k}_{6}[\mathbf{4 a}] \leq 0.2 \mathrm{k}_{5}[3 \mathrm{a}]$ is verified. Within this limit, it is assumed that eq $\mathrm{h}$ is validated as well.

(17) Both reaction 6 and its reverse reaction are bimolecular, and the correct rate law should be: $-\mathrm{d}[\mathbf{4 a}] / \mathrm{dt}=\mathrm{k}_{6}{ }_{6}[\mathbf{4 a}]\left[\mathrm{MeO}^{-}\right]-$ $\mathrm{K}^{\prime}{ }_{6}\left[\mathbf{l a}^{-}\right][\mathrm{DMC}]$. However, once the steady state is reached, since the base is catalytic and DMC is used in a large excess, both [ $\left.\mathrm{MeO}^{-}\right]$and $[D M C]$ should not vary with time. Accordingly, $\mathrm{k}_{6}=\mathrm{k}_{6}^{\prime}\left[\mathrm{MeO}^{-}\right]$and $\mathrm{k}_{-6}=\mathrm{k}_{-6}^{\prime}[\mathrm{DMC}]$.
Table 3. Demethoxycarbonylation of 2-Methoxycarbonyl-2-phenylpropionitrile (4a): Influence of Methanol and Potassium Carbonate

\begin{tabular}{ccccc}
\hline entry & $\begin{array}{c}\mathrm{MeOH}: \mathbf{4 a} \\
\text { (molar ratio) }\end{array}$ & $\begin{array}{c}\mathrm{K}_{2} \mathrm{CO}_{3}: \mathbf{4 a} \\
\text { (molar ratio) }\end{array}$ & $\begin{array}{c}\text { no. of } \\
\text { runs }\end{array}$ & $\begin{array}{c}\mathrm{k}_{\text {obs }} \times 10^{-3} \\
\left(\mathrm{~min}^{-1}\right)^{\mathrm{b}}\end{array}$ \\
\hline 1 & 10 & 2 & 3 & 3.0 \\
2 & 30 & 2 & 3 & 7.6 \\
3 & 10 & 0.1 & 2 & 1.5 \\
4 & 10 & 1 & 3 & 1.9 \\
5 & 10 & 3 & 2 & 3.1 \\
6 & 10 & 4 & 3 & 3.1
\end{tabular}

a All reactions were carried out at $140^{\circ} \mathrm{C}$ using a DMC/substrate molar ratio of $200 .{ }^{b} k_{\text {obs }}$ values were averaged over the number of runs.

However, the further point is why the ratio [2a]/[4a] seems to be constant throughout the reaction (F igure $2 \mathrm{a}$, solid line). This can be discussed through the combination of eqs e and g:

$$
\begin{aligned}
{[\mathbf{2 a}] /[\mathbf{4 a}]=\left[\left(\mathrm{k}_{-2} / \mathrm{k}_{-2}+\mathrm{k}_{5}\right) /\left(\mathrm{k}_{5} / \mathrm{k}_{5}-\mathrm{k}_{6}\right)\right] \times } \\
\left(1-\mathrm{e}^{-\left(\mathrm{k}_{-2}+\mathrm{k}_{5}\right) \mathrm{t}}\right) /\left(\mathrm{e}^{-k_{6} \mathrm{t}}-\mathrm{e}^{-\mathrm{k}_{5} \mathrm{t}}\right)
\end{aligned}
$$

whose corresponding plot (using the $\mathrm{k}_{-2}, \mathrm{k}_{5}$, and $\mathrm{k}_{6}$ values) is the dashed line of Figure $2 \mathrm{a}$. Eq $\mathrm{n}$ exhibits a rather good overlap to the experimental curve. However, at a high reaction time (>250 $\mathrm{min}$ ), the two plots tend to diverge. Equation $n$ correctly predicts that $[\mathbf{2 a}] /[\mathbf{4 a}]$ should increase with time: in fact, $\mathbf{4 a}$ is consumed via the demethoxycarbonylation process (step 6, see also Figure 4), while the amount of $\mathbf{2 a}$ remains constant since its methoxycarbonylation does not take place at $140{ }^{\circ} \mathrm{C}$ (step 2, Scheme 1). This behavior appears less evidently from the experimental dots probably because of the smooth slope of the curve. ${ }^{19}$

In summary, the comparison between $\mathrm{k}_{-2}, \mathrm{k}_{5}$, and $\mathrm{k}_{6}$ showed that the methylation step $(\mathbf{3 a} \rightarrow \mathbf{4 a})$ took place faster than both demethoxycarbonylation reactions $(\mathbf{3} \mathbf{a} \rightarrow \mathbf{2} \mathbf{a}$ and $\mathbf{4 a} \rightarrow \mathbf{1 a})$, which in turn had comparable kinetic constants. Therefore, the methylation step was responsible for driving both equilibria 2 and 6 to the right and accounted for the observed selectivity. The methoxycarbonylation step $(\mathbf{2} \mathbf{a} \rightarrow \mathbf{3} \mathbf{a})$ was instead the rate determining process of the overall reaction.

Step 6 was further investigated to explore whether the reaction rate could be affected by both the base and the coproduct methanol. Thus, in separate experiments, the amount of $\mathrm{K}_{2} \mathrm{CO}_{3}$ and the volume of methanol were changed. Reactions were all of pseudo-first order with respect to the substrate. Results are reported in Table 3 and show the following. (i) The rate constants doubled when the $\mathrm{K}_{2} \mathrm{CO}_{3} / 4$ a ratio ranged from 0.1 to 2 (entries 1 and $3, \mathrm{k}_{\mathrm{obs}}=1.5$ and $3 \times 10^{-3} \mathrm{~min}^{-1}$, respectively); a further increase of the base amount $\left(\mathrm{K}_{2} \mathrm{CO}_{3} / \mathbf{4 a}>2\right)$ did

(18) The concentration [3a]。 was known, being compound 3a the reagent.

(19) To gauge this discrepancy, the ratio $[\mathbf{2 a}] /[\mathbf{4 a}]$ can also be expressed with the assumption that $k_{-2} \sim k_{6}=(1 / 3) k_{5}$. From this assumption, it follows that [2a]/[4a] $=(1 / 6)\left(1-e^{-4 k_{6} t}\right) /\left(e^{-k_{6} t}-e^{-2 k_{6} t} e^{-k_{6} t}\right)$ (eq o) and $[2 \mathrm{a}] /[\mathbf{4 a}]=(1 / 6)\left(2 / \mathrm{e}^{-\mathrm{k}_{6} \mathrm{t}}\right)\left(1+\mathrm{e}^{-2 \mathrm{k}_{6} \mathrm{t}}\right)=(1 / 3) \cosh \mathrm{k}_{6} \mathrm{t}(\mathrm{eq} \mathrm{p})$. The Taylor expansion of cosh $\mathrm{k}_{6} \mathrm{t}$ finally yields $[\mathbf{2 a}] /[\mathbf{4 a}]=(1 / 3) \cosh$ $k_{6} t=1 / 3\left[1-(1 / 2)\left(k_{6} t\right)^{2}+\ldots\right]\left(\right.$ eq q). If the term $(1 / 2)\left(k_{6} t\right)^{2}=0.1$, it can be plausibly neglected. Hence: $[\mathbf{2 a}] /[\mathbf{4 a}]=(1 / 3)(\mathrm{eq} \mathrm{r})$, which is the experimentally determined value (Figure $2 \mathrm{a}$ ). Eq $\mathrm{r}$ implies that $\mathrm{t}=$ $(0.2)^{1 / 2}\left(\mathrm{k}_{6}\right)^{-1} \sim 150 \mathrm{~min}$ : below this reaction time and with the initial approximation for rate constants, the two plots in Figure 2a, overlap within a $10 \%$ error. The same reasoning also indicates that an acceptable overlap (within a 20\% error) still holds until 220 min of reaction. 


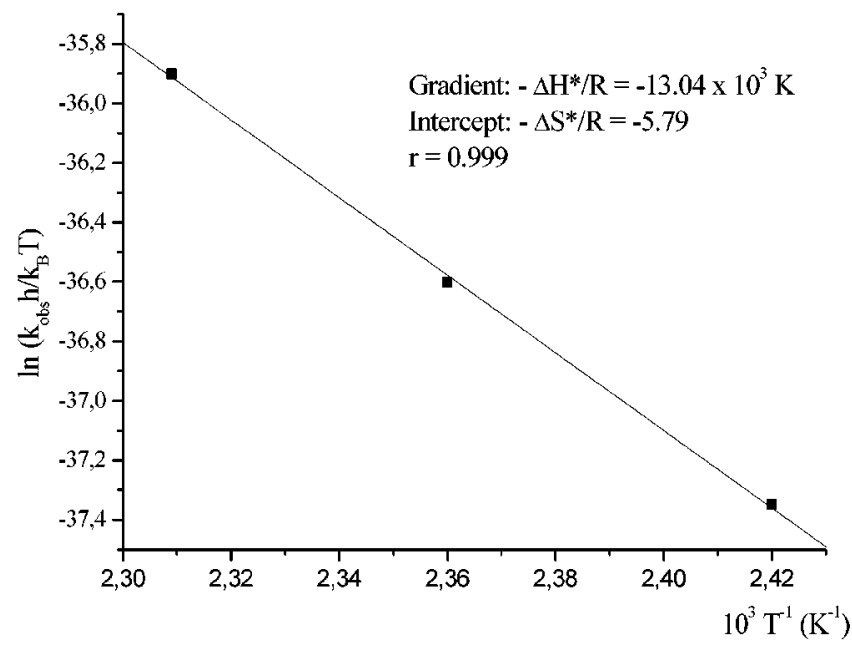

Figure 5. Logarithmic Eyring plot for the methylation of 3awith DMC.

not produce any further rate enhancement (entries 1,5 , and 6), which meant that the catalytic effect of $\mathrm{K}_{2} \mathrm{CO}_{3}$ had a cutoff point probably due to its solubility in DMC. ${ }^{4}$ (ii) The rate constant increased by a factor of approximately 3 when the molar ratio $\mathrm{MeOH} / 4 a$ was tripled (entries 1 and $2, \mathrm{k}_{\mathrm{obs}}=3$ and $7.6 \times 10^{-3} \mathrm{~min}^{-1}$, respectively). Both the base and methanol concentrations had a clear influence on the demethoxycarbonylation reaction, as Scheme 1 predicted (eq 6).

Methylation of the Potassium Salt of 2-Methoxycarbonylphenylacetonitrile $\left[\mathrm{K}^{(+)} \mathrm{PhC}^{(-)}\left(\mathrm{CO}_{2} \mathrm{CH}_{3}\right) \mathbf{C N}\right.$, 3a- ] with DMC: Activation Energy. With the aim of determining the activation energy of the reaction, compound $3 a^{-}$was reacted with $\mathrm{DMC}$ at three different temperatures $\left(140,150\right.$, and $\left.160{ }^{\circ} \mathrm{C}\right)$ in the absence of the heterogeneous base. To avoid the parallel demethoxycarbonylation of $\mathbf{3 a}^{-}$, no methanol was added. The reaction gave $\mathbf{4 a}$ as the sole product, with a pseudo-firstorder rate law whose rate constant $\left(k_{\mathrm{obs}}\right)$ was determined by repeating the reaction five times at each of the chosen temperatures. The corresponding logarithmic plot of the Eyring equation $\left[\ln \left(\mathrm{k}_{\mathrm{obs}} \mathrm{h} / \mathrm{k}_{\mathrm{B}} T\right)=\Delta \mathrm{S}^{*} / \mathrm{R}-\Delta \mathrm{H} * / \mathrm{RT}\right]$ gave a good linear correlation (Figure 5), yielding an activation enthalpy of $112 \mathrm{~kJ} / \mathrm{mol} .20$ This value, compared for example to the activation energy of the hydrolysis of methyl halides $(\approx 100 \mathrm{~kJ} / \mathrm{mol}), 20$ is in agreement with the elevated temperatures $\left(>140{ }^{\circ} \mathrm{C}\right)$ required for the DMC methylation reactions to proceed at appreciable rates.

However, the different reaction environment (absence of methanol and $\mathrm{K}_{2} \mathrm{CO}_{3}$ ) does not allow strict comparison of the kinetic constant to that obtained for step 5 that was previously discussed (in fact, at $140{ }^{\circ} \mathrm{C}$, kobs values were $7.9 \times 10^{-3}$ and $3.2 \times 10^{-2} \mathrm{~min}^{-1}$, respectively).

Methylation of Arylacetic Esters by DMC. Methyl aryl acetates with DMC give mono-C-methyl derivatives through the mechanism outlined in Scheme 1 as well; however, at comparable reaction times, they required a higher temperature $\left(200-220^{\circ} \mathrm{C}\right)$ than nitriles $(180-190$ $\left.{ }^{\circ} \mathrm{C}\right) ., 4,11$ Dimethyl phenylmalonate $\left[\mathrm{PhCH}\left(\mathrm{CO}_{2} \mathrm{Me}\right)_{2}, \mathbf{3 b}\right]$

(20) Maskill, H. In The Physical Basis of Organic Chemistry; Oxford University Press: Oxford, 1989; $\mathrm{p}$ 258. $\mathrm{h}$ and $\mathrm{k}_{\mathrm{B}}$ are Planck and Boltzmann constants. The activation energy was calculated from the gradient of Figure $4\left(\Delta \mathrm{H}^{*} / \mathrm{R}\right)$ using the equation $\mathrm{E}_{\mathrm{a}}=\Delta \mathrm{H}^{*}+\mathrm{RT}$ (by placing $T=423 \mathrm{~K}$, as the mean absolute temperature of the range over which $\mathrm{k}_{\mathrm{obs}}$ values were determined). was made to react with $\mathrm{DMC}$ under the same conditions as for $\mathrm{PhCH}\left(\mathrm{CO}_{2} \mathrm{Me}\right) \mathrm{CN}$ (Substrate:DMC: $\mathrm{MeOH}: \mathrm{K}_{2} \mathrm{CO}_{3}$ in a 1:200:10:2 molar ratio). At $140^{\circ} \mathrm{C}$, a slow demethoxycarbonylation of $\mathbf{3 b}$ was observed (step 2): after $\mathbf{2}$ h, conversion was $4 \%$ and phenyl methyl acetate (2b) was the only product. Instead, at $160{ }^{\circ} \mathrm{C}$, both methylation (step 5) and demethoxycarbonylation of the substrate took place: after $3 \mathrm{~h}$ ( $40 \%$ conversion), the amounts of methyl derivative $\left.\mathrm{PhC}(\mathrm{Me})\left(\mathrm{CO}_{2} \mathrm{Me}\right)_{2} \mathbf{( 4 \mathbf { b }}\right)$ and $\mathbf{2} \mathbf{b}$ were 6 and $34 \%$, respectively.

Although kinetic constants were not determined (reaction times were too long), these results draw an important difference between esters and nitriles: in the case of nitriles, the reactivity of 3a proved that the methylation step was the fastest reaction $\left(k_{5} \approx 3 k_{-2}\right)$, while for esters, the demethoxycarbonylation was the faster process by far.

\section{Conclusions}

The kinetic analysis of the mechanism of Scheme 1 allows the following general considerations. (i) The similarity of $k_{-2}$ and $k_{6}$ reveals that both the starting reagent $\mathbf{2} \mathbf{a}$ and its methyl derivative $\mathbf{1 a}$ undergo demethoxycarbonylation reactions at comparable rates, while the methylation step of the intermediate $\mathbf{4 a}$ is the fastest reaction. (ii) The rate determining step of the overall transformation is the methoxycarbonylation reaction, which is so slow for both $\mathbf{2 a}$ and $\mathbf{1 a}$ that the determination of the related kinetic constants $\left(k_{2}\right.$ and $\left.k_{-6}\right)$ is impracticable at $140{ }^{\circ} \mathrm{C}$. This is probably due to the low concentration of nucleophiles $\mathbf{2} \mathbf{a}^{-}$and $\mathbf{1} \mathbf{a}^{-}$attainable in the presence of a weak base such as $\mathrm{K}_{2} \mathrm{CO}_{3}$.

On the whole, the comparison of the kinetic behavior of the investigated steps reveals that the nonequilibrium methylation reaction is crucial for driving the overall process to completion. In fact, the higher rate of step 5 allows both the rapid consumption of $\mathbf{3 a}$ and the accumulation of $\mathbf{4 a}$, which serves as a reactant for step 6; in other words, both equilibria 2 and 6 are controlled by the irreversible reaction 5 .

The described mechanism evinces the crucial action of the methoxycarbonyl group, which by increasing the acidity of $\mathbf{3}$ increases the concentration of the corresponding anion, $\mathrm{ArC}^{(-)}\left(\mathrm{CO}_{2} \mathrm{CH}_{3}\right) \mathrm{R}\left(3^{-}\right)$, thereby allowing step 5 to occur rapidly. This being established, a key aspect still remains unclear: why $\mathbf{3}^{-}$undergoes direct methylation, while $\mathbf{1}^{-}$or $\mathbf{2}^{-}$does not. Steric and stability factors of the involved anions can be considered, but a more in-depth investigation is necessary. Also, the specific influence of the heterogeneous catalyst must be addressed.

Arylacetoesters behave differently with respect to the nitriles. The reaction of dimethyl phenylmalonate with DMC proves that the demethoxycarbonylation step is easier than the methylation reaction. This fact could be the reason esters need higher temperatures for the reaction to be completed. However, the monomethyl selectivities are comparable (>99\%) for both of the two classes of arylacetic acid derivatives, even using a large excess (200 molar equiv) of the methylating agent.

\section{Experimental Section}

All compounds used were ACS grade and were used without further purification. ${ }^{1} \mathrm{H}$ and ${ }^{13} \mathrm{C}$ NMR spectra were recorded using a Bruker Ac 200 spectrometer (200 and $50 \mathrm{MHz}$, 
respectively) using $\mathrm{CDCl}_{3}$ as the solvent with TMS as the internal standard. GC analyses were performed on a Varian GC 3400 CX apparatus using a 30 m, DB5 capillary column. GC/MS analyses were performed at $70 \mathrm{eV}$ on an HP 5971 mass detector coupled to an HP 5890-Series II gas chromatograph fitted with a $30 \mathrm{~m}$, DB5 capillary column. Melting points were determined on a Büchi 535 melting point apparatus and are uncorrected.

Reactions Carried Out in Autoclave: General Procedure. A stainless steel (AISI 316) autoclave (internal volume of $250 \mathrm{~cm}^{3}$ ) was loaded with a mixture of DMC, the substrate $(0.2 \mathrm{~g})$, the base $\left(\mathrm{K}_{2} \mathrm{CO}_{3}\right)$, methanol (where indicated), and $\mathrm{n}$-decane as the internal standard in the molar ratios reported bel ow (Table 3). At room temperature and before each reaction, air was removed by a purging valve with a $\mathrm{N}_{2}$ stream. The autoclave was placed in a tubular oven heated by an oilcirculating jacket, while the mixture was kept under magnetic stirring. A thermocouple and a needle valve were fixed onto the autoclave head, the former dipping into the reaction mixture and the latter connected to a $1 / 8$ in stainless steel suction pipe that, in turn, was immersed into the reaction mixture. In this way, samples $\left(0.3 \mathrm{~cm}^{3}\right)$ could be withdrawn during the reaction and analyzed by both GC and GC/MS.

2-Methoxycarbonylphenylacetonitrile (3a) and 2-Methoxycarbonylmethyl-2-phenylpropionitrile (4a) were synthesi zed according to established procedures; ${ }^{4,21}$ characterization data were in agreement to those reported in the literature. 22,23

Potassium salt of 2-Methoxycarbonylphenylacetonitrile $\left[\mathbf{K}^{(+)} \mathbf{P h} \mathbf{C}^{(-)}\left(\mathrm{CO}_{2} \mathbf{C H}_{3}\right) \mathbf{C N}, 3 \mathbf{a}^{-}\right]$. A mixture of phenylacetonitrile (20 g, $0.17 \mathrm{~mol}), \mathrm{K}_{2} \mathrm{CO}_{3}(47 \mathrm{~g}, 0.34 \mathrm{~mol})$, and DMF $(100 \mathrm{~g}, 1.37 \mathrm{~mol})$ was loaded in a $250 \mathrm{~mL}$ three-necked flask equipped with a condenser, a dropping funnel filled with DMC $\left(50 \mathrm{~cm}^{3}, 0.52 \mathrm{~mol}\right.$ ), and a glass screw-capped tube (fitted with a rubber silicon septum) used for sample withdrawal. The flask was heated in an oil bath at the reflux temperature $\left(155^{\circ} \mathrm{C}\right)$ while a gentle $\mathrm{N}_{2}$ stream $\left(0.5 \mathrm{~cm}^{3} / \mathrm{min}\right)$ was allowed in and maintained for the whole reaction. At intervals (30 min), small aliquots $\left(1 \mathrm{~cm}^{3}\right)$ of DMC were dripped into the reaction mixture, which was magnetically stirred. The course of the reaction was followed by GC and GC/MS: before each analysis, samples $\left(0.2 \mathrm{~cm}^{3}\right)$ were added with water $\left(1 \mathrm{~cm}^{3}\right)$, acidified with concd $\mathrm{HCl}$ (3 drops), and then extracted with diethyl ether (2 $\mathrm{cm}^{3}$ ). The completion of the reaction was indicated by the

(21) Horning, E. C.; Finelli, A. F. Org. Synth. Vol. Coll. IV; Wiley: 1967, pp 461-63.

(22) Cox, R. J .; O'Hagan, D. J . Chem. Soc., Perkin Trans. 11991 2537-40.

(23) Gompper, R.; Vogt, H.-H. Chem. Ber. 1981, 114, 6-83. presence of 2-methoxycarbonylphenyl propi onitrile as the sole compound. Then, the mixture was cooled to room temperature; $\mathrm{K}_{2} \mathrm{CO}_{3}$ was filtered off and carefully washed with acetone. The filtrate was distilled under vacuum to remove light solvents and $\mathrm{DMF}$; the remaining brown liquid residue was treated with diethyl ether $\left(200 \mathrm{~cm}^{3}\right)$ and allowed to stand overnight in a refrigerator $\left(+4{ }^{\circ} \mathrm{C}\right)$. After filtration, a pale yellow solid was obtained: it was dissolved with acetone $\left(\approx 15 \mathrm{~cm}^{3}\right)$, precipitated with additional diethyl ether $\left(150 \mathrm{~cm}^{3}\right)$, and finally, filtered. The salt $3 \mathbf{a}^{-}$was obtained in a $59 \%$ yield $(23.2$ g). ${ }^{1} \mathrm{H}$ NMR (DMSO- $\left.\mathrm{d}_{6}\right): \delta \mathrm{ppm} 7.55(\mathrm{~d}, 2 \mathrm{H}, \mathrm{J}=7.4 \mathrm{~Hz}$, ortho aromatic), 7.01 (t, $2 \mathrm{H}, \mathrm{J}=7.4 \mathrm{~Hz}$, meta aromatic), 6.81 (t, $1 \mathrm{H}, \mathrm{J}=7.4 \mathrm{~Hz}$, para aromatic), $3.39\left(\mathrm{~s}, 3 \mathrm{H}, \mathrm{COOCH}_{3}\right) .{ }^{13} \mathrm{C}$ NMR (DMSO, $\left.\mathrm{d}_{6}\right): \delta$ ppm 168 (CO), 127, 121, 117 (C, aromatics), $48\left(\mathrm{OCH}_{3}\right)$. The literature reported the formation of the sodium salt $\mathrm{Na}^{(+)} \mathrm{PhC}^{(-)}\left(\mathrm{COOCH}_{3}\right) \mathrm{CN}$ obtained in a methanol solution of sodium methoxide and $3 \mathbf{a}^{24}$

Calibration Curves. The evaluation of rate constants for the steps of Scheme 1, required a high degree of accuracy in the GC analyses. Thus, calibration curves were determined for both compounds $\mathbf{3} \mathbf{a}$ and $\mathbf{4 a}-\mathbf{3} \mathbf{a}^{-}$by using $n$-decane as the internal standard. The general procedure is as follows. A 0.05 $M$ solution of each substrate was prepared using DMC as the solvent. Four aliquots of $5,10,15$, and $20 \mathrm{~cm}^{3}$ were taken and placed separately into four volumetric flasks. Each solution was added with $20 \mathrm{~cm}^{3}$ of a $0.026 \mathrm{M}$ solution of $\mathrm{n}$-decane in DMC and brought to a final volume of $50 \mathrm{~cm}^{3}$ with additional DMC. Then, each solution was analyzed twice by GC. In the case of $3 \mathbf{a}^{-}$, analytical samples of $0.2 \mathrm{~cm}^{3}$ were acidified and extracted with diethyl ether as described in the above preparation of $\mathbf{3} \mathbf{a}^{-}$. The calibration curves were obtained by plotting, for each solution, the ratio of the chromatographic areas of the substrate and the standard versus the concentration of the substrate. Linear fits with $r \geq 0.99$ were obtained in all cases.

Acknowledgment. Murst (I talian Ministry of University and Scientific and Technological Research) and INCA (Interuniversity Consortium Chemistry for the Environment) are gratefully acknowledged for financial support. Prof. Achille Giacometti is also gratefully acknowledged for his hel pful discussion and suggestions on the mathematical aspects of the work.

J 00057699

(24) Abbotto, A.; Bradamante, S.; Pagani, G. A. J . Org. Chem. 1993 $58,449-455$ 